\title{
BMJ Open Patients' perspectives on integrated oral healthcare in a northern Quebec Indigenous primary health care organisation: a qualitative study
}

\author{
Richa Shrivastava, ${ }^{1}$ Yves Couturier, ${ }^{2}$ Naomi Kadoch, ${ }^{1}$ Felix Girard, ${ }^{1}$ \\ Christophe Bedos, ${ }^{3}$ Mary Ellen Macdonald, ${ }^{3}$ Jill Torrie, ${ }^{4}$ Elham Emami ${ }^{3}$
}

To cite: Shrivastava $\mathrm{R}$, Couturier Y, Kadoch N, et al. Patients' perspectives on integrated oral healthcare in a northern Quebec Indigenous primary health care organisation: a qualitative study. BMJ Open 2019;9:e030005. doi:10.1136/ bmjopen-2019-030005

- Prepublication history for this paper is available online. To view these files please visit the journal online (http://dx.doi org/10.1136/bmjopen-2019030005).

Received 22 February 2019 Revised 26 May 2019 Accepted 24 June 2019

Check for updates

(c) Author(s) (or their employer(s)) 2019. Re-use permitted under CC BY-NC. No commercial re-use. See rights and permissions. Published by BMJ.

${ }^{1}$ Faculty of Dentistry, Université de Montréal, Montréal, Québec, Canada

${ }^{2}$ School of Social Work, Université de Sherbrooke, Sherbrooke, Québec, Canada ${ }^{3}$ Faculty of Dentistry, McGill University, Montréal, Québec, Canada

${ }^{4}$ Public Health Department, Cree Board of Health and Social Services of James Bay, Mistissini, Québec, Canada

Correspondence to

Elham Emami;

elham.emami@mcgill.ca

\section{ABSTRACT}

Objective Patient-centred care is considered to be an important element in the evaluation of integrated healthcare and has been effective in addressing oral health disparities. This study explored the patients' perspectives of patient-centred integrated care in oral health services integrated into a primary healthcare organisation serving a northern Quebec Cree population.

Design This study used a multiple case study design within a qualitative approach and developmental evaluation methodology. Two theoretical models, Picker's Principles of Patient-Centred Care and Valentijn's Rainbow Model of Integrated Care, guided data collection and data analysis. The thematic analysis included transcription, debriefing, codification, data display and interpretation.

Setting This study was conducted in purposefully selected four Cree communities of Northern Quebec.

Participants Adult patients in need of oral healthcare and who attended the local dental clinic were identified and recruited by maximum variation sampling and snowball techniques.

Outcome measures Patients' perspectives of patientcentred integrated oral healthcare.

Results Data analysis generated six major themes: enhanced accessibility, creating supportive environment, building trust through shared decision making, appreciation of public health programmes, raising oral health awareness and growing cultural humility among healthcare providers. Patients identified the integration of dental care into primary healthcare with respect to co-location, provision of free oral healthcare services, care coordination and continuity of care, referral services, developing supportive environment, shared decision making, oral health promotion and culturally competent care.

Conclusion These results confirmed that patient-centred care is an important element of integrated care. Patients valued the use of this concept in all domains and levels of integration. They recommended to further strengthen the clinical integration by involving parents in oral health promotion as well as optimising care coordination and empowering a supportive environment in organisational integration.

\section{Strengths and limitations of this study}

- To our knowledge, this study is the first worldwide research that explored the patients' perspective in regard to the integration of oral healthcare in an Indigenous primary healthcare organisation.

- In-depth individual interviews allowed a rich exploration of patients' perspectives on patient-centred integrated oral healthcare in this organisation.

- Results suggest that patient-centred care is an important element of integrated care and it can be facilitated by the factors such as co-location, provision of free dental services, oral health promotion, referral services, care coordination, supportive environment, shared decision making and culturally competent services.

- Results are based on small sample size of patients recruited from Cree community hospitals.

\section{INTRODUCTION}

Throughout the late 20th century, influential works such as Engel's biopsychosocial model and Balint's Patient-Centered Medicine in North America and Europe have inspired the shift of healthcare service delivery towards a holistic patient-oriented approach. ${ }^{1-3}$ During the late 1980s, patient-centred care (PCG) was conceptualised and defined by the Institute of Medicine as: "providing care that is respectful of, and responsive to, individual patient preferences, needs and values, and ensuring that patient values guide all clinical decisions'. ${ }^{4}$ PCC applies to all levels of healthcare organisations irrespective of population and ethnic or cultural groups. ${ }^{35}$ Research has demonstrated that implementing PCC in healthcare organisations can reduce healthcare costs and improve healthcare quality and outcomes, patient adherence, patient satisfaction and care provider satisfaction, and has the potential to alleviate healthcare disparities. $^{36-9}$ 
The WHO has also developed a global strategy for programmes that involve PCC in integrated care to deal with the barriers encountered by current health systems such as demographic transition, highly prevalent chronic diseases and subsequent economic burden. ${ }^{8}$ As defined by the WHO, integrated care is 'bringing together inputs, delivery, management and organisation of services related to diagnosis, treatment, care, rehabilitation and health promotion'. ${ }^{10}$

Several healthcare associations and organisations including the Canadian Nurses Association, Canadian Medical Association and Health Action Lobby have identified PCC as one of the five foundations for integrated care, along with access, relational continuity, management continuity and information continuity. ${ }^{811} 12$ Moreover, ascribing a significant role to PCC in oral healthcare, several oral healthcare organisations in Europe, Australia and North America have introduced PCC as a core element in the evaluation of integrated healthcare services. ${ }^{34} 13-15$ The PCC model of integration of oral healthcare within primary health has been highlighted to be effective in addressing oral health disparities among Indigenous communities. ${ }^{16}{ }^{17}$ Moreover, the role of PCC becomes imperative in the case of Indigenous populations considering historical trauma due to colonisation and assimilation policies. ${ }^{18}$ These historical traumas included loss of homeland, loss of family for children in residential schools, loss of traditional cultural practices as well as mistrust, distress and fear towards the intentions of non-Indigenous people. ${ }^{19}{ }^{20}$ Hence, consideration of Indigenous patients' cultural values, beliefs and preferences, as well as their holistic vision of health, is essential in the implementation of PCC in Indigenous populations. ${ }^{18}$

According to the recent WHO report there is still lack of evidence focusing on the application of people-centred integrated care in primary healthcare settings. ${ }^{8}$ Furthermore, as highlighted in a systematic review by Mills $e t$ al in 2014, there is still a gap in regard to the application of PCC concepts from patients' perspectives and in oral health research. ${ }^{3}$ Also, Harnagea et al emphasised in a recent scoping review the lack of evidence on the outcomes of integrated primary oral healthcare programmes among disadvantaged populations. ${ }^{21}$ Therefore, the objective of this study was to explore patients' perspectives and experiences in regard to patient-centred integrated oral healthcare in a primary healthcare organisation serving a northern Quebec Cree population.

\section{METHODS}

\section{Study design}

This collaborative study was part of a larger Canadian Institutes of Health Research-funded project entitled 'Oral Health Integrated into Primary Care: Participatory Evaluation of Implementation and Performance in Quebec Cree Communities' ${ }^{22}$ We adopted a multiple case study design within a qualitative approach and developmental evaluation methodology. ${ }^{23} 24$ The case study design allows an in-depth understanding of a single or small number of 'cases' in their real-world context'. ${ }^{24}$

Developmental evaluation addresses the need of the key stakeholders by building a partnership between them and researchers in the assessment of emerging initiatives in their organisation. ${ }^{23}$ Accordingly, the project started with a planning phase which included a 3 days stay in one of the Cree communities (Mistissini), followed by a 2 days video conferencing workshop few months later (Mistissini and Montreal) ${ }^{25}$ The details of the workshop have been published previously. ${ }^{25}$ In the planning phase, the research team conducted several oral presentations and had several focus group discussions and individual faceto-face meetings with Cree community health centres' administrators, community workers, healthcare providers and patients. During these various communications, different aspects of the study, such as research objectives, data collection, recruitment strategies, as well as conceptual frameworks were discussed.

We followed the ethical guidelines of Ownership, Control, Access and Possession (OCAP) for First Nations. ${ }^{26}$ This manuscript has been prepared according to the Standards for reporting qualitative research. ${ }^{27}$

\section{Study setting, participants and data collection}

Over 18000 Cree people of Eeyou Istchee inhabit nine remote communities in the eastern James Bay region of northern Quebec, Canada. ${ }^{28}$ The health and social services of these communities are provided by the Cree Board of Health and Social Services of James Bay (CBHSSJB). ${ }^{15}$ This organisation developed two Strategic Regional Plans, 2004-2014 and 2016-2021, which mandate a model for the integrated delivery of health and social services in the Cree communities including oral healthcare. ${ }^{1529}$ Each community has a Community Miyupimatiisiuun (wellness) Centre (CMC) that provides healthcare and social services through a team of primary healthcare providers, including para-professional community health representatives. ${ }^{28}$ Each community has a well-equipped local dental clinic where free services are provided by dentists and dental hygienists. ${ }^{28}$

This study was conducted in four Cree communities that were purposefully selected based on population size as well as on geographical, cultural, healthcare and oral care characteristics. We used maximum variation sampling and snowball techniques to identify and recruit adult patients ( $\geq 18$ years) in need of oral healthcare and who attended the local dental clinic in 2016-2017. In-depth audio-recorded interviews, on average $60 \mathrm{~min}$ long, were conducted in English or French by two research team members trained in qualitative methods. These team members had no existing relationship with the participants. We designed the semistructured interview guide based on the Rainbow Model of Integrated Care. ${ }^{30}{ }^{31}$ Data collection and analysis were performed concurrently until data saturation was reached. ${ }^{32}{ }^{33}$ Data saturation was reached after the 11th interview; nevertheless, data 
collection was continued up to 14 th interview to ensure the saturation level.

\section{Data analysis}

Data analysis included transcription, debriefing, codification, data display, thematic content analysis and triangulation. ${ }^{32}$ We used the eight Picker Principles of PCC and Valentijn's Rainbow Model of Integrated Care as conceptual models to guide exploring and determining the scope of elements of PCC within the integrated care network. ${ }^{30} 3134$ Picker's principles comprise: respect for patient's preferences, information and education, access to care, emotional support, involvement of family and friends, continuity and transition, physical comfort and coordination of care. ${ }^{34}$ The domains of the Rainbow Model of Integrated Care are characterised by three categories: scope, types and enablers of integration. Scope comprises person-based and population-based care; types include system, organisational, professional and clinical integration; and enablers include functional and normative integration. ${ }^{3031}$ We performed a combination of deductive and inductive thematic content analysis using ATLAS.ti V.1.6.0 software (ATLAS.ti, GmbH; Berlin, Germany). ${ }^{35}$ The deductive approach encompassed the creation of provisional categories derived a priori from the conceptual models. This was embedded with an inductive approach, which consisted in adapting these provisional categories into new categories and themes based on the content of the transcripts. ${ }^{32} 35$ Two research trainees (RS, NK) independently performed the analysis and then discussed the emerging codes in detail until they achieved a consensus on emergent categories and themes. The thematic analysis was then revised by other research team members (EE, YC, FG, CB, JT, MEM). The results of the study were discussed and cross validated with community stakeholders.

\section{Patient and public involvement}

Patients have been actively engaged and accepted to participate in the study. The study results will be shared with the community members via CHBSSJB.

\section{RESULTS}

Table 1 presents the demographic profile of the 14 participants. Among them, four were working as healthcare providers who attended the dental clinic as patients for their treatments. The following six themes were generated from our thematic analysis.

\section{Enhanced accessibility}

Participants highlighted the impact of the integration of oral health into primary healthcare in facilitating the access to oral healthcare in terms of the easily accessible location of the dental clinic as well as its proximity within the CMC. Most of the patients perceived co-location as expedient, especially in case of complications and emergencies.

\begin{tabular}{ll}
$\begin{array}{l}\text { Table } 1 \\
(\mathrm{n}=14)\end{array}$ & Sociodemographic characteristics of participants \\
\hline Characteristics & No. participants \\
\hline $\begin{array}{l}\text { Gender } \\
\text { Male }\end{array}$ & 2 \\
\hline Female & 12 \\
\hline Age, years & \\
\hline $31-40$ & 7 \\
$41-50$ & 3 \\
\hline $51-60$ & 4 \\
\hline Ethnicity & \\
\hline Cree & 13 \\
\hline Non-Cree & 1 \\
\hline Employment & \\
Employed & 13 \\
Non-employed & 1 \\
\hline
\end{tabular}

I love how it's [location of the clinic] two in one, like almost... I know elsewhere it's completely separate. (Participant 3)

I think it would be better to be close just in case sometimes complications do happen, you know it's low chance but it does happen so. (Participant 4)

They also valued the provision of free oral healthcare services within integrated healthcare.

[dental services are covered] It makes a difference... I take advantage of it... I know it's there... that's why I always come. (Participant 11)

[fact that the treatments are free] It's the best thing ever! I love it! (Participant 3)

Participants also appreciated referral mechanisms of integrated care at the CBHSSJB organisation. These referral mechanisms facilitated provision of specialised dental treatments by the linkage of primary healthcare to secondary or tertiary levels of healthcare.

I love how [the orthodontic service] has weekend visits so we don't have to miss work, most of the time I bring my kids. (Participant 3)

Patients acknowledged the need for better care coordination to tackle the long waitlists and to enable follow-ups. They also linked the problem of long waitlists with the limited number and non-permanency of dental care providers. Nonetheless, they valued the competencies of dental care providers in providing quality dental treatments.

My son came once then they never called back... I did the fill-up sheet... they contacted me 3 months later... and it was like a pain no. 5. ... and the time when we got here, they had to pull out his tooth (Participant 13) 
The waiting lists and I don't think they are being called! I saw that on Facebook that people complain that .... they made appointments for them because they were in pain and there is still no call. (Participant 1)

I think ... we would... just need another dentist. Because that's what keeps the long list. (Participant 6)

\section{Creating supportive environment}

Patients expressed the importance of enabling the care, especially for those with dental fear and anxiety, by creating a supportive environment at the clinic. They preferred the dental clinic environment and oral healthcare team to be more welcoming and empathetic, which in turn can provide psychological support for them.

Yeah, the approach, the environment. You know the ... positivity in the room. And here like I said they walk in and they're terrified. They won't even open their mouth. (Participant 4)

It needs to be behavior: 'Hi, how are you? When was the last time you saw the dentist?' ... To be more humane, more sympathetic. It will be very nice for someone to come ... instead of filling the form, to talk with the receptionist and to leave with an appointment ... that's ideal. (Participant 13)

\section{Building trust through shared decision making}

Participants highlighted the importance of including patients in integrated care by engaging them in shared treatment decision making. Most of the patients recognised the value of information given by oral healthcare providers on treatment options and respecting their choices and preferences.

To be engaged in the treatments, some do and some don't. I had a bad experience with my one dentist ... The other one saying, 'Ok if that's the way you want it.' Then they'll just tell us, 'This is what's gonna happen if you do it this way.' (Participant 4)

Furthermore, participants expressed that shared decision making reinforced building trust with the healthcare providers and improved the quality of care.

I think empowering the person to take part in the process, is not a bad thing. It actually establishes more of a relation-trust. (Participant 5)

\section{Appreciation of public health programmes}

Participants appreciated the continuity of care via CBHSSJB public health programmes, which linked promotive and preventive oral healthcare to primary healthcare. These public programmes included daycarebased and school-based oral health programmes for children and $\hat{A}$ Mashkûpimâtsît Awash programme for pregnant mother and child care where promotive and preventive dental services were offered by dental and non-dental care providers.

My grandson is in kindergarten now ... They [dental care providers] do some kinds of things at the school ... They just teach him how to brush, they take the big teeth model and they teach them to use the brush ... and they give them little toothbrushes in packages. (Participant 7)

\section{Raising oral health awareness}

Patients discussed lack of oral health awareness among the community residents. They expressed the need to promote oral health and increase oral health literacy via creating awareness programmes and engaging parents in oral health education.

I think, for me ... I learned how to take care of my teeth at home with my parents. (Participant 9)

The parents ... should be, I think it's maybe the number one spot. [Some of the parents should be educated more?] Yes. Cause I know some parents have dropped out of school very early and they didn't go through a lot of what indicate a parent when it's, like I said ... the dentist visits the schools... and a lot of parents don't have that. (Participant 4)

Patients proposed novel ideas for awareness campaigns via radio, television, social media and short videos and also during social events such as health nights (youth awareness event), youth festivals and sports events.

Videos, short videos like showing someone brushing their teeth like two seconds of that ... flossing and then a really nice smile, ... different products that could be used, just like ... two minutes video ... the beginning of the video to make it like that interesting ... it can go on there... they can share it. (Participant 13)

Here it's sports, hockey—to advertise ... It would be very helpful. People might not listen but you know it gets in their heads. (Participant 4)

\section{Growing cultural humility among healthcare providers}

Participants appreciated having Indigenous people among dental teams and hearing Indigenous language during provision of care. Patients also highly valued non-Cree health professionals' interest in learning their culture, traditions and language by attending cultural activities and traditional ceremonies that helped them in developing affinity and building trust with the community. They also praised non-Indigenous care providers' attempts to learn and speak Indigenous language to make them feel comfortable during treatment.

I like that [dental care providers] like to learn. Like they go with the family when they go in the bush or whenever, to learn. Or to the gravel pit ... There's lots of things you can learn over there. They're always doing stuff ... (Participant 8 ) 
Even the dentists. They tried the Cree [Cree word] 'keep your mouth opened' and they're amazing! (Participant 3)

\section{DISCUSSION}

It has been two decades since the concept of PCC was first introduced to integrated care. ${ }^{36}$ Shaw et al identify PCC as a crux of integrated care and recommend including the patient's perspective as an organising principle of service delivery. ${ }^{36}$ To our knowledge, this study is the first worldwide research that explored the patients' perspective in regard to the integration of oral healthcare in an Indigenous primary healthcare organisation.

Study findings demonstrate that these patients valued the integration of oral healthcare in primary healthcare in regard to co-location, free oral healthcare services, coordination and continuity of care. They highlighted the importance of respecting their perspectives in clinical decision making, integrating Indigenous personnel in dental teams, optimising care coordination, providing a supportive environment and oral health promotion. The emphasis on culturally sensitive care, development of a more supportive environment and parental engagement for oral health promotion were also linked to addressing the historical impacts such as intergenerational trauma, loss of cultural practices, fear and mistrust and loss of parenting skills.

We used Picker's principles of PCC for analysing the results due to their relevance, comprehensiveness and ability to conceptualise various elements of PCC. ${ }^{37}$ Our findings support these principles as essential elements in delivering PCC in integrated oral health care ${ }^{34}$ (table 2). According to the literature, the patient is a focal point of integrated care ${ }^{38}{ }^{39}$ Singer et al defined integrated patient care and developed a framework based on this definition: 'patient care that is coordinated across professionals, facilities and support systems; continuous over time and between visits; tailored to the patients' needs and preferences; and based on shared responsibility between patient and caregivers for optimising health' ${ }^{39}$ Our findings emphasising the significance of care coordination, continuity of care, shared decision making and the need for patients' health awareness in PCC are consistent with the results of research studies in other healthcare disciplines in Australia, the USA and various European countries. ${ }^{38} 40-42$ This can suggest that the key features of PCC are the same in integrated healthcare irrespective of patients' profile, their type of health problems and the nature of the healthcare organisation. Similarly, Goodwin et al compared seven case studies on successful integrated health and social service programmes for people with complex needs in seven different countries: Australia, Canada, The Netherlands, New Zealand, Sweden, the UK and the USA. ${ }^{43}$ All these programmes have incorporated PCC by engaging patients and caregivers, and identify PCC as the basis for implementing integrated care programmes. ${ }^{43}$ Accordingly, our results align with a culturally sensitive community-based integrated care Te Whiringa Ora (Care Connections) programme in New Zealand for rural and Indigenous chronic patients in emphasising culturally relevant PCC by engaging patients and family members. ${ }^{43}{ }^{44}$ Our study results are also consistent with the evidence on valuing the role of Indigenous care providers in delivering PCC, including the Te Whiringa Ora programme. ${ }^{44}$

Our results demonstrating the value of clinical shared decision making and supportive environment as key features of PCC are coherent with the systematic review and original research conducted by Mills et al on PCC in general dental practice and from both care providers' and patients' perspectives. ${ }^{3}{ }^{46}$ Moreover, our results are also underpinned by the recommendation of the Department of Health Resources and Services Administration in the USA and other studies on the need for integration of dental and medical care and the importance of the co-location in achieving success in PCC. ${ }^{17} 42$

Table 2 Interconnections between the Picker's Principles of $\mathrm{PCC}^{32}$ and patient-centred integrated oral healthcare as reported by Cree patients

\begin{tabular}{ll}
\hline Themes & Picker's principles \\
\hline Theme 1. Enhanced accessibility & Access to care. \\
Theme 2. Creating supportive environment & Coordination of care. \\
& $>$ Ehotional support. \\
Theme 3. Building trust through shared decision making & $>$ Respect for patient's preferences. \\
Theme 4. Appreciation of public health programmes & $>$ Continuity and transition. \\
Theme 5. Raising oral health awareness & $>$ Information and education. \\
Theme 6. Growing cultural humility among healthcare providers & $>$ Respect for patient's preferences.
\end{tabular}

PCC, patient-centred care. 
Table 3 Interconnections between the dimensions of integrated care demonstrated in Rainbow Model ${ }^{29} 30$ and patientcentred integrated oral healthcare as reported by Cree patients

\begin{tabular}{lll} 
Themes & $\begin{array}{l}\text { Key features of each dimension for PCC } \\
\text { reported by Cree patients }\end{array}$ & $\begin{array}{l}\text { Domains of integrated care } \\
\text { (Rainbow Model of Integrated } \\
\text { Care) }\end{array}$ \\
\hline Theme 1. Enhanced accessibility & $\begin{array}{l}\text { Co-location } \\
\text { Financial mechanisms } \\
\text { Interprofessional collaboration }\end{array}$ & $\begin{array}{l}\text { Organisational } \\
\text { Functional } \\
\text { Organisational }\end{array}$ \\
& Professional competencies & Professional \\
\hline $\begin{array}{l}\text { Theme 2. Creating supportive } \\
\text { environment }\end{array}$ & Inadequate human resources & Organisational \\
\hline $\begin{array}{l}\text { Theme 3. Building trust through shared } \\
\text { decision making }\end{array}$ & Creating supportive environment & Organisational \\
\hline $\begin{array}{l}\text { Theme 4. Appreciation of public health } \\
\text { programmes }\end{array}$ & Interaction between professional and client & Clinical \\
\hline $\begin{array}{l}\text { Theme 5. Raising oral health awareness } \\
\text { Theme 6. Growing cultural humility }\end{array}$ & Carents as oral health promotion champions & Clinical \\
\hline \begin{tabular}{l} 
among healthcare providers \\
\hline
\end{tabular} & Linking cultures & Clinical \\
\hline
\end{tabular}

The themes from our study support the results of the comprehensive scoping reviews and original research conducted by Harnagea et al showing the validity of Rainbow framework in term of domains (table 3) and facilitators of integrated care including culturally relevant services and existence of public oral health programmes. ${ }^{17} 21$ Our study also identified barriers to integration similar to those identified by Harnagea et al including human resource issues such as lack of trained dental care providers. ${ }^{1721}$

These results should be interpreted within the consideration of few limitations. First, the study included a small sample of patients visiting the Cree dental clinics. This may have influenced the study results since it did not include the perspectives of those who are not using dental services. Second, few men participated in the study. This could be explained by the fact that women more use dental services than men. ${ }^{47-50}$ Finally, though the qualitative approach is not intended for generalising results, the study participants represented a degree of heterogeneity in terms of demographics and oral health status. The focus on a specific setting and organisation in this qualitative study generated rich information that prepares the ground for further research on the integration of oral health into primary healthcare.

\section{CONCLUSION}

Patients at CBHSSJB acknowledged incorporation of PCC in integrating oral health into primary healthcare and expressed the need to further strengthen the clinical and organisational integration. Our results support that fostering PCC can improve integrated healthcare performance.
Acknowledgements We are grateful to all study participants from Cree communities for sharing their experiences as well as the community stakeholders who helped us to recruit them.

Contributors RS contributed to study concept and design, acquisition, data collection, reviewing transcripts, coding, analysis and interpretation of data; drafting and critical revision of the manuscript. YC contributed to acquisition, data collection, revising analysis and critical revision of the manuscript. NK contributed to study concept and design, acquisition, reviewing transcripts, coding, analysis and interpretation of data, and drafting the manuscript . FG contributed to acquisition, data collection, revising analysis and critical revision of the manuscript. CB contributed to acquisition, revising analysis and critical revision of the manuscript. MEM contributed to acquisition, revising analysis and critical revision of the manuscript. JT contributed to study concept and design, acquisition, revising analysis and critical revision of the manuscript. EE contributed to study concept and design, acquisition, data collection, revising analysis and critical revision of the manuscript.

Funding We received funds from funding agencies including Canadian Institutes of Health Research, Quebec Population Health Research Network, Institut de recherche en santé publique de l'Université de Montréal, Fondation de l'Ordre des dentistes du Québec, the Network for Canadian Oral Health Research, and the Network for Oral and Bone Health Research (CIHR grant number: Gl1-145123).

Competing interests None declared.

Patient consent for publication Not required.

Ethics approval Ethics approval for this study was obtained from the Institutional Review Board of the Université de Montréal, McGill University and permission from the Research Committee of the Cree Board of Health and Social Services of James Bay.

Provenance and peer review Not commissioned; externally peer reviewed.

Data sharing statement № additional data are available.

Open access This is an open access article distributed in accordance with the Creative Commons Attribution Non Commercial (CC BY-NC 4.0) license, which permits others to distribute, remix, adapt, build upon this work non-commercially, and license their derivative works on different terms, provided the original work is properly cited, appropriate credit is given, any changes made indicated, and the use is non-commercial. See: http://creativecommons.org/licenses/by-nc/4.0/.

\section{REFERENCES}

1. Balint $\mathrm{E}$. The possibilities of patient-centered medicine. J R Coll Gen Pract 1969;17:269-76. 
2. Engel GL. The biopsychosocial model and the education of health professionals. Ann N Y Acad Sci 1978;310:169-81.

3. Mills I, Frost J, Cooper C, et al. Patient-centred care in general dental practice--a systematic review of the literature. BMC Oral Health 2014;14:64

4. Institute of Medicine (US) Committee on Quality of Health Care in America. Crossing the quality chasm: a new health system for the 21st Century. Washington (DC): National Academies Press (US), 2001.

5. Saha S, Beach MC, Cooper LA. Patient centeredness, cultural competence and healthcare quality. J Natl Med Assoc 2008;100:1275-85.

6. Stewart M, Brown JB, Donner A, et al. The impact of patientcentered care on outcomes. J Fam Pract 2000;49:796-804.

7. Loignon C, Allison P, Landry A, et al. Providing humanistic care: dentists' experiences in deprived areas. J Dent Res 2010;89:991-5.

8. World Health Organization. WHO global strategy on people-centred and integrated health services: interim report. Geneva, Switzerland: World Health Organization, 2015.

9. Epstein RM, Fiscella K, Lesser CS, et al. Why the nation needs a policy push on patient-centered health care. Health Aff 2010;29:1489-95.

10. Gröne O, Garcia-Barbero M, WHO European Office for Integrated Health Care Services. Integrated care: a position paper of the WHO European Office for Integrated Health Care Services. Int J Integr Care 2001:1:e21.

11. Canadian Nurses Association, Canadian Medical Association, Health Action Lobby. Integration: a new direction for canadian health care. a report on the health provider summit process. $2013 \mathrm{https}: / / \mathrm{www}$. cna-aiic.ca/-/media/cna/files/en/cna_cma_heal_provider_summit_ transformation to integrated care e.pdf?la=en\&hash=094811D9 4F0487A196901715B5FE14516ACA194E.

12. European Commission. A new drive for primary care in Europe: Rethinking the assessment tools and methodologies- report of the expert group on health systems performance assessment. Luxembourg: European Union, 2018.

13. American Dental Association. Dental quality alliance. http://www.ada org/en/science-research/dental-quality-alliance/about-dqa (accessed on 2019 Jan 10).

14. Australian Commission on Safety and Quality in Health Care. Patientcentred care: Improving quality and safety through partnerships with patients and consumers. Sydney: ACSQHC, 2011.

15. Cree Board of Health and Social Services of James Bay. Strategic regional plan to improve health and social services "Miyupimaatisiiun" - "Building a Strong and Healthy Cree Nation", 2004

16. Petersen PE. The world oral health report 2003: continuous improvement of oral health in the 21st century: the approach of the WHO Global Oral Health Programme. . Geneva, Switzerland: World Health Organization, 2003:31. 3-24.

17. Harnagea $\mathrm{H}$, Couturier $\mathrm{Y}$, Shrivastava $\mathrm{R}$, et al. Barriers and facilitators in the integration of oral health into primary care: a scoping review. BMJ Open 2017;7:e016078.

18. McMillan F, Kampers D, Traynor V, et al. Person-centred care as caring for country: an indigenous australian experience. Dementia 2010;9:163-7.

19. Burnette CE, Sanders S, Butcher HK, et al. Illuminating the lived experiences of research with indigenous communities. Journal of Ethnic And Cultural Diversity in Social Work 2011;20:275-96.

20. Cidro J, Zahayko L, Lawrence H, et al. Traditional and cultural approaches to childrearing: preventing early childhood caries in Norway House Cree Nation, Manitoba. Rural Remote Health 2014;14:2968

21. Harnagea $\mathrm{H}$, Lamothe $\mathrm{L}$, Couturier $\mathrm{Y}$, et al. From theoretical concepts to policies and applied programmes: the landscape of integration of oral health in primary care. BMC Oral Health 2018;18:23.

22. Emami E, Torrie JE, Couturier Y, et al. Oral health integrated into primary care: participatory evaluation of implementation and performance in quebec cree communities, operating grant: population health intervention research - pathways: canadian institutes of health research. 2016 http://webapps.cihr-irsc.gc.ca/ decisions/p/project_details.html?applld=343763\&lang=en (accessed on 10 September 2017).

23. Patton MQ. Developmental evaluation: Applying complexity concepts to enhance innovation and use. New York, NY: Guilford Press, 2011.

24. Yin RK. Case Study Research: Design and methods. USA: SAGE publications, Inc, 2014.

25. Emami; E, Couturier; Y, Girard; F, et al. Integration of oral health into primary health care organization in cree communities: a workshop summary. J Can Dent Assoc 2016;82(g30).

26. First Nations Information Governance Centre. Ownership, Control, Access and Possession (OCAPTM): The Path to First
Nations Information Governance. Ottawa, ON: The First Nations Information Governance Centre. 2014 https://fnigc.ca/sites/ default/files/docs/ocap_path_to_fn_information_governance_en_ final.pdf.

27. O'Brien BC, Harris IB, Beckman TJ, et al. Standards for reporting qualitative research: a synthesis of recommendations. Acad Med 2014;89:1245-51.

28. Cree health. Cree board of health and social services of James Bay. http://www.creehealth.org/ (Accessed 25 October 2018)

29. Cree Board of Health and Social Services of James Bay. Strategic regional plan- Striving to achieve Nishiiyuu Miyupimaatisiiun together 2016-2021. Chisasibi, QC: Cree Board of Health and Social Services of James Bay, 2017.

30. Valentijn PP. Rainbow of chaos- $A$ study into the theory and practice of integrated primary care. The Netherlands: Tilburg University, 2015.

31. Valentijn PP, Schepman SM, Opheij W, et al. Understanding integrated care: a comprehensive conceptual framework based on the integrative functions of primary care. Int $J$ Integr Care 2013;13:e010.

32. Elo S, Kyngäs $\mathrm{H}$. The qualitative content analysis process. J Adv Nurs 2008;62:107-15.

33. Patton MQ. Qualitative research \& evaluation methods: Integrating theory and practice. 4 edn. Thousand Oaks, California: SAGE Publications Inc, 2015

34. Gerteis M. Picker/Commonwealth Program for Patient-Centered Care,. Through the patient's eyes: understanding and promoting patient-centered care. San Francisco (CA): Jossey-Bass, 1993.

35. Fereday J, Muir-Cochrane E. Demonstrating rigor using thematic analysis: a hybrid approach of inductive and deductive coding and theme development. Int J Qual Methods 2006;5:80-92.

36. Shaw S, Rosen R, Rumbold B. An overview of integrated care in the NHS- What is integrated care? London: Nuffield Trust, 2011.

37. Paparella G. Person-centred care in Europe: a cross-country comparison of health system performance, strategies and structures - Policy briefing. Picker Institute Europe: Oxford, 2016.

38. Greenfield G, Ignatowicz AM, Belsi A, et al. Wake up, wake up! It's me! It's my life!patient narratives on person-centeredness in the integrated care context: a qualitative study. BMC Health Serv Res 2014;14:619.

39. Singer SJ, Burgers J, Friedberg M, et al. Defining and measuring integrated patient care: promoting the next frontier in health care delivery. Med Care Res Rev 2011;68:112-27.

40. Cooper H, McMurray A, Ward L, et al. Implementing patient-centred care in the context of an integrated care program. Int $J$ Care Coord 2015;18:72-7.

41. van der Heide I, Snoeijs S, Quattrini S, et al. Patient-centeredness of integrated care programs for people with multimorbidity. Results from the European ICARE4EU project. Health Policy 2018;122:36-43.

42. Brownlee B. White paper - Oral health integration in the PatientCentered Medical Home (PCMH) environment: case studies from community health centers. Seattle, (WA): Qualis Health, 2012.

43. Goodwin N, Dixon A, Anderson G, et al. Providing integrated care for people with complex needs. Lessons from seven international case studies. London: King's Fund, 2014.

44. Carswell P. Te Whiringa Ora: person-centred and integrated care in the Eastern Bay of Plenty, New Zealand. Int J Integr Care 2015;15:e014.

45. Toronto: Ontario's Aboriginal Health Access Center. A Aboriginal Health Access Center/Aboriginal CHC Leadership Circle Co-Chairs. Bringing Order to Indigenous Primary Health Care Planning and Delivery in Ontario: AHACs and Aboriginal CHCs Response to Patients First: A Proposal to Strengthen Patient-Centred Heath Care in Ontario. 2016 https://www.allianceon.org/sites/default/files/ documents/AHAC\%20Patients\%20First\%20Response\%20Final\% 20-\%20April\%202016.pdf.

46. Mills I, Frost J, Kay E, et al. Person-centred care in dentistry--the patients' perspective. Br Dent J 2015;218:407-13. discussion 413.

47. Skaret E, Raadal M, Kvale G, et al. Gender-based differences in factors related to non-utilization of dental care in young Norwegians. A longitudinal study. Eur J Oral Sci 2003;111:377-82.

48. Lutfiyya MN, Gross AJ, Soffe B, et al. Dental care utilization: examining the associations between health services deficits and not having a dental visit in past 12 months. BMC Public Health 2019;19:265.

49. Hamasha AA-H, Alshehri A, Alshubaiki A, et al. Gender-specific oral health beliefs and behaviors among adult patients attending King Abdulaziz Medical City in Riyadh. Saudi Dent J 2018;30:226-31.

50. Sohn W, Ismail A, Amaya A, et al. Determinants of dental care visits among low-income African-American children. J Am Dent Assoc 2007;138:309-18. 